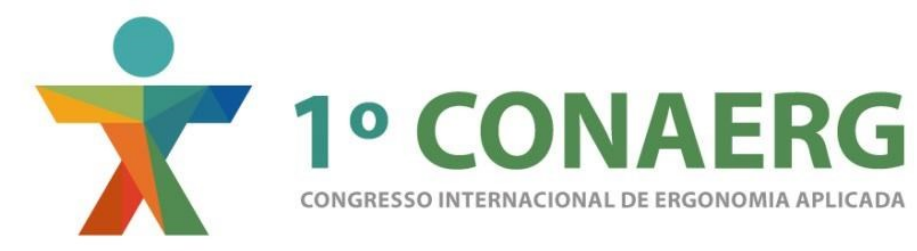

\title{
AVALIAÇÃO AMBIENTAL EM PONTO DE VENDA DE JOALHERIA, RELOJOARIA E ÓTICA
}

\author{
Vera Helena Moro Bins Ely (1); \\ Fernanda Olinto (2); \\ Mariana Silva Villela (3);
}

(1) Universidade Federal de Santa Catarina, Doutora em Engenharia de Produção

e-mail: vera.binsely@gmail.com

(2) Universidade Federal de Santa Catarina, Mestranda na Pós Graduação em Arquitetura e Urbanismo

e-mail: fernandaolinto@gmail.com

(3) Universidade Federal de Santa Catarina, Mestranda na Pós Graduação em Arquitetura e Urbanismo

e-mail: arq.marianavillela@gmail.com

\begin{abstract}
RESUMO
Com o objetivo de investigar a qualidade ambiental do ponto de venda, este artigo apresenta o resultado da avaliação do ambiente de trabalho de um comércio do segmento de joalheria, relojoaria e ótica. A escolha do local surgiu pela sua aparente demanda de reestruturação do espaço físico e a busca por utilizar conceitos da ergonomia e psicologia ambiental como suporte para avaliação do ambiente e para o bem-estar de seus usuários. Utilizando métodos como visita exploratória, observação e entrevista foi possível compreender o funcionamento do negócio, suas especificidades, a opinião dos funcionários e, assim, suas reais necessidades. Notou-se não só carência em melhorias na ambiência do espaço e no conforto dos trabalhadores do local, como também a ausência de um posicionamento de marca adequado ao negócio, o que influenciou no acréscimo de conceitos de marketing à pesquisa, como auxílio e aporte teórico para a geração de melhores recomendações.
\end{abstract}

PALAVRAS-CHAVE: arquitetura comercial, avaliação ambiental, ergonomia do ambiente construído.

\section{ABSTRACT}

In order to investigate the environmental quality of a selling point, this article presents results of the evaluation of a bussiness work environment in the jewelry, watchmaking and optics segment. The location choice of the study appeared by its apparent demand of restructure to the physical space and the search of using the concepts of ergonomics and environmental psychology as support for environmental assessment, as well as for the welfare of its users. Using methods as exploratory visits, observation and interview it was possible to understand business operation, their specificities and also know the opinion of employees and thus their real needs. Then, it was noted not only lack in improvements in the ambience of the space and comfort of the workers, as well as the absence of a proper business brand positioning, this caracteristic influenced the addition of marketing concepts to the research, as a support and theoretical contribution to the generation of better recommendations. 
KEYWORDS: comercial architecture, environmental assessment, ergonomics of of the built environment.

\section{INTRODUÇÃO}

O dinamismo do varejo e da economia demanda aos lojistas estratégias de negócio não apenas criativas, mas também integradoras. Investimentos são avaliados de acordo com possibilidades de incremento de vendas, fortalecimento de marca, satisfação do cliente, entre outros (KOETLER, 2000). Presente no marketing mix - o conjunto de estratégias de uma empresa para ajustar sua oferta à demanda de mercado de um produto ou serviço - o ponto de venda (PDV) é o canal de distribuição de produtos e/ou serviços que se consolidou a partir da intensificação da economia industrial, no início do século XX (VAROTTO, 2006). Com a evolução deste cenário, um nicho de atuação para arquitetos - especialmente na área da arquitetura de interiores - ficou popularmente conhecido como arquitetura comercial.

Considerando o PDV como parte de uma estratégia de marketing integrado, é importante também a correta divulgação da imagem, posicionamento e benefícios das marcas e produtos expostos, assim como uma experiência agradável para seus usuários. Como um espaço de vivência humana, sua eficiência reside também na adequação ambiental às necessidades de seus usuários. "Para o projeto de um ambiente que responda às necessidades do usuário na realização de determinada tarefa, é importante avaliar quais os fatores que concorrem para a qualidade ambiental" (BINS ELY; TURKIENICZ, 2005, p.78). Assim, a avaliação da experiência do usuário passa pela compreensão da relação entre a atividade e o ambiente onde ela se realiza.

A análise de um ambiente visando a sua adequação às atividades humanas é o objetivo da Ergonomia de Ambientes Construídos (VILLAROUCO, 2009). Entendendo a relação entre ser humano, ambiente e atividade realizada no espaço como um sistema, engloba-se no olhar ergonômico a compreensão de fatores como a organização do trabalho, as tarefas, as atividades, as posturas, o conforto. Essa análise revela, portanto, a eficiência ou ineficiência do sistema, propondo transformações que melhorem o ambiente.

A contribuição da Psicologia Ambiental, por sua vez, reside na análise da percepção dos usuários sobre o ambiente, assim como seu comportamento. Compreender anseios e necessidades humanas, a lógica de utilização do espaço e da realização das atividades é de fundamental importância para a avaliação ambiental.

Este artigo apresenta a avaliação de um ambiente de trabalho realizado em ponto de venda, durante os meses de maio e junho de 2016. O objetivo é compreender a aplicação da ergonomia em ambiente físico, assim como aspectos de humanização e comportamento dos usuários, a partir do aporte teórico da Ergonomia e da Psicologia Ambiental. Foi selecionado pelas pesquisadoras um ponto de venda do segmento de joalheria, relojoaria e ótica, pelo critério de sua aparente demanda de reestruturação do espaço físico. Ao se conhecer melhor a empresa e sua organização, identificou-se a necessidade da inclusão dos conceitos de marketing como aporte teórico.

\section{REFERENCIAL TEÓRICO}

Entende-se que a transdisciplinaridade favorece a apreensão da complexidade na interação entre ser humano, ambiente e atividade. Com uma visão integradora do escopo de cada área de conhecimento - Arquitetura, Ergonomia do Ambiente Construído, Psicologia Ambiental e Marketing - fundamentou-se esta avaliação ambiental.

A arquitetura é o cenário de boa parte da atividade humana. De acordo com Norberg-Schulz (2013), ela transforma-se de um espaço sem identidade em lugar específico quando provê significado a quem o habita. Seja qual for o propósito da habitação, a percepção de sua qualidade passa pelo favorecimento das atividades que ocorrem em seus ambientes, 
atendendo tanto as necessidades funcionais quanto as necessidades subjetivas dos seus usuários.

$\mathrm{Na}$ visão antropocêntrica de que a arquitetura deve adequar o ambiente ao seu usuário, alinham-se os conhecimentos da Ergonomia e da Psicologia Ambiental - disciplinas cujo foco central também está no ser humano - de forma que seu escopo de conhecimentos contribui para projetos arquitetônicos de maior qualidade aos usuários.

Oriunda do estudo do trabalho enquanto atividade, condições de execução e resultado obtido, a Ergonomia é uma ciência que analisa esse sistema e seu funcionamento (GUÉRIN; LAVILLE; DANIELLOU; DURAFOURG; KERGUELEN, 2001). A realização da atividade depende de uma combinação entre as condições internas do indivíduo (conhecimentos, experiência, saúde, etc.) e as condições externas do trabalho (objetivos, exigências, meios disponibilizados pela organização) (FALZON, 2007). Isso pode envolver saúde, satisfação pessoal, produtividade, resultados financeiros, etc. Segundo Guérin et al (2001), a análise ergonômica propicia subsídios para uma intervenção de transformação e melhoria nas atividades de trabalho.

Entre os meios disponibilizados pela organização está o ambiente (físico) de trabalho. De acordo com Bins Ely e Turkienicz (2005), as características de um ambiente podem dificultar ou facilitar a realização das atividades. A interação entre o ambiente, seus usuários e atividades vem sido estudada pela Ergonomia do Ambiente Construído, cujas pesquisas visam identificar a contribuição dos ambientes para as atividades nele desenvolvidas, a sua influência no comportamento e bem-estar do usuário e adaptações do usuário ao ambiente (MORAES; MONT'ALVÃO, 2004).

Cada estudo ergonômico do ambiente construído permitirá um aprofundamento na interação entre ambiente, atividade e usuário, de diferentes naturezas. Conhecendo-se os problemas, as limitações ou os constrangimentos da interação, será possível contribuir com recomendações, diretrizes ou soluções projetuais para futuros ambientes de mesma natureza.

Diversos fatores são considerados nos estudos ergonômicos de ambientes. Fisicamente, são considerados desde os elementos e atributos mais gerais do ambiente - como materiais de revestimentos e acabamentos, leiaute, mobiliário, conforto térmico, nível de ruídos, iluminação, acessibilidade, circulação, etc. - até os mais particulares dos usuários, como posturas, medidas antropométricas, alcances, etc. (OLIVEIRA; MONT'ALVÃO, 2015; MORAES; MONT'ALVÃO, 2003). Um entendimento mais global da interação entre ambiente, usuário e atividade, no entanto, contempla necessariamente aspectos subjetivos, tais como a percepção e o comportamento do usuário. Neste âmbito, os conhecimentos da Psicologia Ambiental são de fundamental importância.

Os sistemas sensoriais humanos permitem ao indivíduo captar informações do ambiente por meio dos mecanismos fisiológicos perceptivos (os sistemas definidos por Gibson em 1966 como orientação, háptico, auditivo, paladar-olfativo e visual) (LOMBARDO, 1987). Embora as informações ambientais sejam as mesmas para diferentes indivíduos, a captação das informações pode diferir conforme a idade, a saúde ou a necessidade, por exemplo. No entanto, a maneira como cada informação percebida é tratada individualmente é o que dá o caráter subjetivo do processo perceptivo. A partir desta elaboração pessoal da percepção o indivíduo tomará decisões acerca de seu comportamento. Percepção e comportamento, portanto, são conceitos essenciais para a compreensão da experiência humana no ambiente.

No que tange ao arquiteto, sua responsabilidade reside em procurar não só compreender o usuário para adequar o projeto do ambiente às suas necessidades, mas também conhecer os estímulos ambientais que interferem na sua saúde e bem-estar. Esses conhecimentos, aliados à habilidade do projetista, interferem na qualidade de um projeto arquitetônico. Reconhecer a relevância da percepção ambiental no comportamento humano é pressuposto para um projeto mais humanizado. 
Ittelson et al (1974) destacam que a Psicologia Ambiental não vê o homem como um produto passivo do seu meio, mas como um ser que age sobre ele e também é influenciado pelo mesmo. Em se tratando da relevância para a avaliação ambiental em questão, destacam-se alguns conceitos cruciais dessa interação humano-ambiental, expressas no comportamento humano: territorialidade (controle físico do espaço), privacidade (controle do acesso à informação/ a si mesmo) e aglomeração (percepção de espaço disponível).

Na convergência da Psicologia Ambiental com a Arquitetura surgiu uma importante vertente que identifica fatores essenciais para a humanização de ambientes. De acordo com Tissot (2016), um dos principais autores sobre humanização é o arquiteto norte-americano Roger Ülrich. Ele identifica, a partir de estudos científicos, três componentes relacionados à promoção do bem-estar: controle do ambiente (controle de iluminação, som, privacidade, entre outros), suporte social (áreas para convívio social) e distrações positivas (elementos como jardins, vistas para natureza, entretenimento). Tissot (2016) acrescenta um quarto fator essencial à humanização de ambientes: o suporte às atividades. Sendo assim, além dos conhecimentos apontados, faz-se necessário contemplar neste referencial a natureza do objeto de estudo e sua atividade: um ponto de venda. A arquitetura de um ambiente comercial, além do foco antropocêntrico intrínseco à Arquitetura, à Ergonomia e à Psicologia Ambiental, possui um foco mercadológico, sendo necessária a compreensão de marketing e a relevância do PDV em suas estratégias.

De acordo com Koetler (2000), marketing envolve vendas e lucros empresarias, mas também descobrir e satisfazer necessidades: "é quando existe uma necessidade, de fato, e uma empresa a identifica e apresenta uma solução cabível". Uma estratégia de marketing reúne basicamente quatro elementos: preço, produto, promoção e praça, as quais são definidas pela empresa que oferta o produto e/ou serviço. Esses elementos básicos, ao longo dos estudos de marketing, podem variar de autor para autor. Porém, praça é invariavelmente o local onde o consumidor procura pelo produto, o que inclui o ponto-devenda.

Como espaço de vivência humana, o objetivo primordial do PDV é a exposição de produtos para demonstração e/ou experimentação pelos clientes potenciais. O ponto de venda é o espaço no qual a construção de uma marca passa pela experiência real e concreta. De acordo com Underhill (2009), "O marketing, a propaganda, as promoções e a localização podem atrair os consumidores, mas depois cabe à mercadoria, aos funcionários e à própria loja transformá-los em compradores“. O autor ainda defende que a concepção dos ambientes deve direcionar o comportamento do cliente para o propósito do negócio, de forma que aspectos ambientais como iluminação, acessibilidade, dimensionamento, setorização, entre outros, são de fundamental importância para a experiência positiva do cliente.

Uma visão integrada do marketing, portanto, envolve a construção de uma marca, a experiência do consumidor e as vendas. No que tange aos aspectos ambientais do ponto de venda, é possível investigar se ele cumpre com a representação adequada dos valores da empresa, assim como se ele favorece a experiência do cliente com o produto ou serviço, complementando os aspectos arquitetônicos, ergonômicos e psicológicos da avaliação ambiental.

\section{METODOLOGIA}

Caracteriza-se esta avaliação como uma pesquisa exploratória e qualitativa, com abordagem transdisciplinar. Com objetivo de avaliar a qualidade ambiental do ponto de venda a partir da percepção dos usuários e suas atividades, foram escolhidos diferentes instrumentos e técnicas: pesquisa bibliográfica e documental, visitas exploratórias, walkthrough, observação e inquirições (entrevistas semiestruturadas e questionário).

Segundo Zeisel (2006), as técnicas de observar e perguntar são complementares na compreensão das atividades. Observar nos permite conhecer as atividades e 
comportamentos externamente. Perguntar nos permite conhecer as condições internas e subjetivas inerentes à atividade. Desta forma, as técnicas de Visita Exploratória e Walkthrough permitiram às pesquisadoras as primeiras impressões sobre as interações entre pessoa, ambiente e atividade. A partir dos princípios da Análise Ergonômica do Trabalho (AET) (GUÉRIN et al, 2001) foi possível fundamentar a análise da demanda, a tarefa e a atividade do local. A Observação Sistemática possibilitou o conhecimento externo desta interação e as inquirições permitiram o conhecimento interno. A categorização de Zeisel sobre o que observar permite ao pesquisador a verificação da adequação do ambiente às necessidades do uso, tanto pela observação do ambiente em uso quanto pela observação dos vestígios ou traços deixados pelo uso. São elas: subprodutos de uso, adaptações para o uso, manifestações de identidade, públicas e contexto. Além desta categorização, elencaram-se aspectos físicos e comportamentais a serem observados, a partir do escopo de conhecimentos da Ergonomia - categorização dos problemas ergonômicos de Moraes e Mont’alvão (2003) - assim como os conceitos da Psicologia Ambiental de territorialidade, privacidade e aglomeração.

Foram realizadas quatro visitas ao local, de aproximadamente duas horas e trinta minutos cada. Na primeira visita realizaram-se o conhecimento do local (Visita Exploratória), o Walkthrough com proprietário e a Entrevista Semiestruturada com o proprietário. Na segunda visita, o levantamento físico-funcional (Visita Exploratória) e as Entrevistas Semiestruturadas com dois funcionários. Na terceira visita realizaram-se as Observações Sistemáticas das atividades, assim como a aplicação do Questionário Nórdico (KUORINKA et al, 1987). Na quarta visita, realizaram-se novas Observações Sistemáticas das atividades dos funcionários. Ressalta-se que as pesquisadoras procuraram entrevistar proprietários e funcionários em dias diferentes e individualmente, para que se expressassem sem constrangimentos, devido à ausência de sala privativa no local.

\section{RESULTADOS E DISCUSSÃO}

Os principais resultados obtidos são destacados em cinco tópicos apresentados a seguir, são eles: 1) apresentação da empresa; 2) caracterização do universo de pesquisa; 3 ) apresentação do ambiente; 4) apresentação dos postos de trabalho; 5) análise da demanda, tarefa e atividade; 6) percepção ambiental.

\subsection{Apresentação da empresa}

O estabelecimento analisado corresponde à loja matriz da marca especializada no comércio e conserto de joias, relógios e óculos. A empresa, consolidada no mercado, atua há 22 anos em horário de funcionamento comercial (segunda à sexta-feira das 9:00 às 18:00 horas e sábados das 9:00 às 12:00 horas) e possui, além do proprietário, dois funcionários trabalhando no local.

A loja é organizada em dois setores distintos, de acordo com a função exercida: administração e atendimento. Destinado ao uso do proprietário, o setor de administração lida com as questões financeiras, operacionais, de planejamento e burocráticas. O setor de atendimento trata diretamente com o cliente e é subdivido em atendimento específico para vendas de produtos e em atendimento para consertos e reparo de peças. Ambos setores exigem contato com o cliente através de atividades de cobrança de pagamento, porém a função de conserto, quando executada, demanda maior concentração e privacidade.

O negócio analisado não possui nicho de mercado específico de atuação, priorizando o preço acessível e o bom atendimento como artifício para a captação de clientes. Contudo, atualmente inexiste uma estratégia definida em relação às melhorias do ambiente e reposicionamento de marca para atração de novos clientes. 


\subsection{Caracterização do universo de pesquisa}

O universo de pesquisa é composto por três indivíduos do gênero masculino: o proprietário envolvido no setor de administração e atendimento - e dois funcionários do setor de atendimento. Todos realizam vendas e consertos. O Proprietário, 43 anos, possui trinta anos de experiência no ramo, é destro e pratica exercícios físicos. O Funcionário 1, 34 anos, possui quatorze anos de experiência, é canhoto e pratica exercícios físicos. O Funcionário 2 , 24 anos, possui três anos de experiência, é destro e não pratica exercícios físicos.

\subsection{Apresentação do ambiente}

O ambiente estudado, apresentado na Figura 01, está inserido em contexto urbano, em um calçadão de grande relevância no centro da cidade. Presente no segundo pavimento de um edifício comercial, a área útil da loja é de $35 \mathrm{~m} 2$ e disponibiliza seis seções distintas: atendimento, administração, consertos, copa, banheiro e sacada. Não existem divisórias físicas entre as seções de atendimento, consertos e administração, são visualmente integradas. Apesar de permitir uma maior amplitude, esta integração gera muita informação visual, tanto pelos produtos expostos quanto pelas bancadas de trabalho.

\subsection{Apresentação dos postos de trabalho}

A setorização dos postos de trabalho contempla: Administração, Conserto de relógios, Conserto de joias, Conserto de óculos, Consertos rápidos e Recepção. A Administração possui um posto de trabalho fixo, utilizado pelo proprietário. Conserto de joias e relógios possuem bancadas específicas e contam com apoio de um equipamento de polimento posicionado na copa. O posto de Conserto de joias é utilizado pelo Funcionário 1, assim como o posto de Conserto de óculos. O posto de Conserto de relógios é utilizado pelos Funcionários 1 e 2. O posto de Consertos rápidos é utilizado por todos (proprietário e funcionários), assim como as mesas e bancadas da recepção. Para um melhor entendimento, a Figura 01 demonstra a localização em planta baixa de cada um dos postos de trabalho de forma setorizada.

Figura 01 - Imagens do ambiente e setorização dos postos de trabalho e marcação das vitrines
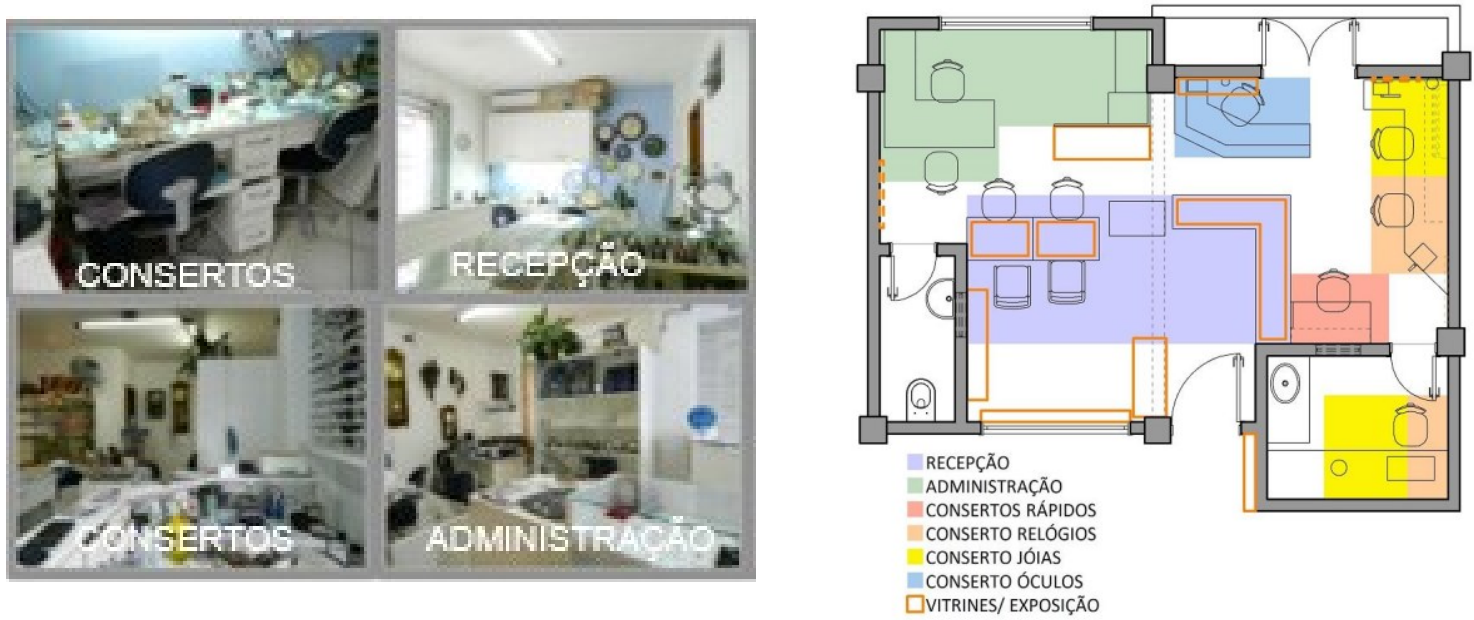

Fonte: Pesquisadoras

\subsection{Análise da demanda, tarefa e atividade}

Entende-se por demanda o problema a ser analisado; por tarefa o que o trabalhador deve realizar e as condições para a realização; por atividade o comportamento real na execução da tarefa. Para esclarecer a diferença entre tarefa e atividade, a ergonomia aborda o termo "tarefa" se referindo ao trabalho que é prescrito pela chefia, pelos colegas ou pela própria 
pessoas (antes de realizar a sua atividade), já o termo "atividade" denota o trabalho que é efetivamente realizado (CYBIS, 2007).

\subsubsection{Demanda}

Este estudo foi suscitado pelos desafios iniciais apresentados: múltiplas funções de trabalho específicas (joalheiro, relojoeiro, ourives, vendedor, etc.) em um espaço aparentemente delimitado, com excesso de elementos e informações-e, ainda, sem possuir um posicionamento de marca claro. Após as primeiras visitas exploratórias e entrevistas, a demanda definida consistiu em otimizar o rendimento do estabelecimento como um todo, procurando soluções práticas para a melhoria do ponto de venda. Definiu-se também solucionar os problemas dos usuários trabalhadores do local em seus postos de trabalho.

\subsubsection{Tarefa}

O objetivo da análise da tarefa é compreender a rotina de trabalho e, posteriormente, sua relação com as atividades desenvolvidas. Devido à ausência de prescrição formal, foram feitas entrevistas com o universo de participantes para compreensão de suas tarefas, assim como pesquisa das funções de relojoeiro, ourives, atendente balconista e gerente comercial pela Classificação brasileira de Ocupações (CBO). O comércio e reparação de óculos não tem atuação definida na CBO.

A rotina do Proprietário é abrir e fechar a loja, realizar atendimentos e funções administrativas (compra de mercadoria, manutenções, atividades financeiras, estratégias empresariais, etc.) e, eventualmente, consertos de joias, óculos e relógios. A rotina do Funcionário 1 é abrir e fechar a loja (revezando-se com o Proprietário) e realizar atendimentos e consertos de joias, óculos e relógios. Também atua como ourives na fabricação de alianças. A rotina do Funcionário 2 realizar atendimentos e consertos de relógios. Também atua como assistente no conserto de joias.

A prioridade é o atendimento ao cliente. Portanto, caso estejam realizando consertos ou outras atividades, fazem uma pausa e atendem o cliente. Todos estão aptos a vender os tipos de produtos da loja. Em relação aos consertos de joias, óculos e relógios, cada especialidade possui especificidades próprias em procedimentos, ferramentas e acessórios. Cada bancada está organizada com as peças e ferramentas de cada especialidade. Já os equipamentos encontram-se distribuídos pelas bancadas e em parte da copa, por falta de espaço mais adequado. Destaca-se a demanda de acuidade visual no exercício destas tarefas, devido ao minúsculo tamanho de muitas peças necessárias aos consertos.

\subsubsection{Atividade}

A partir do conhecimento acerca das tarefas efetuadas no local em questão, pôde-se coletar informações suficientes para a análise da atividade. Para esta etapa, o método de observação foi de extrema importância. Por meio de anotações, registros fotográficos e vídeos, obteve-se a relação entre a tarefa prescrita e a atividade efetivamente realizada.

Foi possível notar, durante a análise da atividade, uma coerência entre tarefas prescritas e atividades. No entanto, foi possível identificar detalhes não salientados durante a descrição da tarefa, assim como constrangimentos, dificuldades e adaptações para a realização das mesmas. Tal assunto será abordado na seção de Diagnóstico e Recomendações.

\subsection{Percepção ambiental}

A percepção ambiental acerca do espaço construído é necessária para o entendimento das impressões e sensações obtidas pelos usuários do espaço, assim como seu comportamento e necessidades fundamentais. No caso desta pesquisa, o foco foram os usuários que trabalham no local. 
Os usuários foram questionados, durante as entrevistas, sobre os atributos e elementos arquitetônicos do espaço. A Tabela 01 demonstra quais foram os aspectos do ambiente abordados e sua avaliação positiva ou negativa pela visão dos usuários. Ainda, em comparativo com a sua percepção, foram incluídas as percepções das pesquisadoras obtidas pelo método de observação. Isso permitiu a correlação dos dados.

Tabela 01 - Percepção ambiental

\begin{tabular}{|c|c|c|c|c|c|}
\hline \multirow[t]{2}{*}{ Fatores } & \multirow{2}{*}{$\begin{array}{l}\text { Aspectos } \\
\text { Iluminação }\end{array}$} & \multicolumn{2}{|l|}{ Funcionários } & \multicolumn{2}{|l|}{ Pesquisadoras } \\
\hline & & $\begin{array}{l}\text { Apropriada para } \\
\text { necessidades de } \\
\text { trabalho. }\end{array}$ & ( & $\begin{array}{l}\text { Inapropriada, falta de } \\
\text { iluminação individual, } \\
\text { direcionável e dimerizável. }\end{array}$ & $\Theta$ \\
\hline \multirow{4}{*}{ Ambientais } & Ventilação & $\begin{array}{l}\text { Considerada } \\
\text { adequada. }\end{array}$ & (†) & $\begin{array}{l}\text { Considerada confortável, } \\
\text { presença de abertura e ar } \\
\text { condicionado. }\end{array}$ & (A) \\
\hline & Aroma/cheiro & $\begin{array}{l}\text { Não houveram } \\
\text { problemas. }\end{array}$ & (A) & $\begin{array}{l}\text { Local apropriado quanto à estas } \\
\text { questões. }\end{array}$ & (t) \\
\hline & Som/barulho & $\begin{array}{l}\text { Considerado } \\
\text { agradável. }\end{array}$ & $(+)$ & $\begin{array}{l}\text { Barulho da rua não interfere. } \\
\text { Falta de som ambiente. }\end{array}$ & 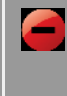 \\
\hline & Temperatura & $\begin{array}{l}\text { Considerada } \\
\text { agradável. }\end{array}$ & ( & $\begin{array}{l}\text { Considerada confortável, } \\
\text { abertura de sacada e ar } \\
\text { condicionado. }\end{array}$ & (A) \\
\hline \multirow{3}{*}{ Funcionais } & Mobiliário & $\begin{array}{l}\text { Visto como adequado } \\
\text { às suas necessidades. }\end{array}$ & ( & $\begin{array}{l}\text { Visto como inadequado, falta de } \\
\text { organização, manutenção, e } \\
\text { adaptação antropométrica. }\end{array}$ & 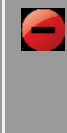 \\
\hline & Leiaute & $\begin{array}{l}\text { Ajustes no } \\
\text { posicionamento de } \\
\text { máquinas e área de } \\
\text { atendimento. }\end{array}$ & ( & $\begin{array}{l}\text { Posicionamento inapropriado } \\
\text { dos móveis e máquinas, falta } \\
\text { de setorização e acesso } \\
\text { dificultado às vitrines. }\end{array}$ & $\varepsilon$ \\
\hline & $\begin{array}{l}\text { Fluxos e } \\
\text { circulações }\end{array}$ & $\begin{array}{l}\text { Não houve relato } \\
\text { negativo. }\end{array}$ & ( & $\begin{array}{l}\text { Dimensões inadequadas e } \\
\text { fluxo travado pelo mobiliário. }\end{array}$ & 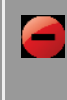 \\
\hline \multirow{3}{*}{ Estéticos } & $\begin{array}{l}\text { Revestimentos } \\
\text { materiais cores }\end{array}$ & $\begin{array}{l}\text { Alteração dos } \\
\text { revestimentos. }\end{array}$ & 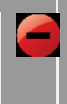 & Alteração dos revestimentos. & $E$ \\
\hline & $\begin{array}{l}\text { Contato com } \\
\text { exterior } \\
\text { (entorno) }\end{array}$ & $\begin{array}{l}\text { Não houve relato } \\
\text { negativo. }\end{array}$ & $(+$ & $\begin{array}{l}\text { Contato reduzido com o } \\
\text { exterior, falta de vegetação e } \\
\text { sacada mal aproveitada. }\end{array}$ & $E$ \\
\hline & Conforto & Sem queixas. & ( & Falta de mobiliário ergonômico. & $E$ \\
\hline Ergonômicos & Produtividade & Intensa. & ( & Falta de privacidade. & E \\
\hline
\end{tabular}

Fonte: Pesquisadoras

Os resultados obtidos na relação da percepção ambiental demonstram grande diferença quanto a satisfação geral dos funcionários em confronto com a opinião das pesquisadoras. A visão positiva dos funcionários pode ser explicada pelo aspecto social: a boa relação existente entre estes e o proprietário, incentivando um ambiente de trabalho amigável e agradável aos trabalhadores, superando a percepção acerca dos aspectos negativos. $O$ 
relacionamento entre os usuários que trabalham no local, assim como o deles com os clientes é avaliado como muito boa pelo universo da amostra, fato confirmado pela percepção das pesquisadoras.

\section{DIAGNÓSTICO E RECOMENDAÇÕES}

A partir dos resultados e discussão dos métodos aplicados, o diagnóstico e as recomendações visam proporcionar uma síntese do que foi abordado, apresentando propostas para melhoria do espaço avaliado. A Tabela 02 a seguir apresenta esta síntese. As categorias selecionadas para a elaboração do diagnóstico abrangem os resultados ergonômicos por meio da classificação proposta por Mont alvão e Moraes (2003) para problemas do sistema ser humano - tarefa - máquina como Interfacial, Acional, Espacial/Arquitetural de Interiores, Químico-ambiental e Biológico. Ainda, para um enfoque mais específico no comportamento, há categorias que advém dos conceitos da Psicologia Ambiental, tais como territorialidade, privacidade e aglomeração. Por fim, também foram selecionadas as categorias dos vestígios de comportamento de Zeisel (2006), como adaptações para o uso e subprodutos de uso.

\section{Tabela 02 - Categorização do problemas e recomendações}

\begin{tabular}{|c|c|c|}
\hline Categorias & Problemas & Recomendações \\
\hline 1. Interfacial & $\begin{array}{l}\text { Postura inadequada na bancada } \\
\text { de consertos gerais, pescoço } \\
\text { curvado, pés e cotovelos sem } \\
\text { apoio. }\end{array}$ & $\begin{array}{l}\text { Cadeiras com maiores possibilidades de regulagens, } \\
\text { com encosto para os cotovelos, uso de apoio dos } \\
\text { pés; Alteração de altura do assento e de bancada. }\end{array}$ \\
\hline 2. Acional & $\begin{array}{l}\text { Posicionamento inadequado de } \\
\text { utensílios fixos para o uso de } \\
\text { destros ou canhotos. }\end{array}$ & $\begin{array}{l}\text { Reposicionamento dos utensílios no leiaute visando } \\
\text { a mão dominante do funcionário de uso mais } \\
\text { frequente. Extensão para facilitar a movimentação } \\
\text { do equipamento. }\end{array}$ \\
\hline $\begin{array}{l}\text { 3. Espacial/ } \\
\text { Arquitetural de } \\
\text { Interiores }\end{array}$ & $\begin{array}{l}\text { Fluxos e circulações } \\
\text { comprometidas com dimensões } \\
\text { inapropriadas para a passagem } \\
\text { de dois funcionários; falta de } \\
\text { vegetação e materiais mais } \\
\text { aconchegantes. }\end{array}$ & $\begin{array}{l}\text { Leiaute refeito com dimensões adequadas, } \\
\text { permitindo livre fluxo sem comprometer o trabalho; } \\
\text { Aproveitamento da sacada para uso de vegetação;; } \\
\text { Utilização de madeira como material para maior } \\
\text { conforto. }\end{array}$ \\
\hline 4. Químico-ambiental & $\begin{array}{l}\text { Trabalho com fogo e ácido que } \\
\text { geram fumaça e resíduos, assim } \\
\text { como elementos como pó de } \\
\text { ouro. }\end{array}$ & Inclusão de sistema de exaustão no local. \\
\hline 5. Biológico & $\begin{array}{l}\text { Higiene deficiente ao trabalhar } \\
\text { com alimentos próximos à } \\
\text { máquina de polimento; falta de } \\
\text { limpeza correta dos resíduos } \\
\text { gerados e de organização das } \\
\text { ferramentas. }\end{array}$ & $\begin{array}{l}\text { Separação da área de Copa com a área de Ourives, } \\
\text { isolando máquinas do local de refeições; Painéis de } \\
\text { ferramentas nas paredes laterais das bancadas de } \\
\text { consertos para organização e espaço livre.. }\end{array}$ \\
\hline 6.Territorialidade & $\begin{array}{l}\text { Não há nenhum tipo de } \\
\text { separação e delimitação do } \\
\text { território entre o setor da } \\
\text { administração com o restante da } \\
\text { loja. }\end{array}$ & $\begin{array}{l}\text { Isolamento físico (divisória em vidro fixo e porta de } \\
\text { correr); Materiais da divisória permitem a } \\
\text { visibilidade parcial da loja - posicionamento } \\
\text { invertido da mesa de trabalho permite o controle } \\
\text { visual da área de atendimento; Maior organização e }\end{array}$ \\
\hline
\end{tabular}




\begin{tabular}{|c|c|c|}
\hline & & $\begin{array}{l}\text { privacidade; Maior isolamento acústico; } \\
\text { Possibilidade de reuniões e atendimentos } \\
\text { privados/exclusivos. }\end{array}$ \\
\hline 7. Privacidade & $\begin{array}{l}\text { Bancada de consertos rápidos } \\
\text { próxima ao atendimento da } \\
\text { recepção sem barreira física que } \\
\text { dê privacidade, permitindo o } \\
\text { alcance do cliente à mesa de } \\
\text { trabalho. }\end{array}$ & $\begin{array}{l}\text { Relocação da bancada de consertos rápidos e } \\
\text { utilização de vidro criando separação física, porém } \\
\text { não visual, entre cliente e funcionário. }\end{array}$ \\
\hline 8. Aglomeração & $\begin{array}{l}\text { Área de entrada dos clientes e } \\
\text { local de atendimento com espaço } \\
\text { reduzido para espera, causando } \\
\text { sensação de aglomeração. } \\
\text { Vitrines com falta de } \\
\text { aglomeração por proximidade de } \\
\text { acordo com o tipo de produto } \\
\text { (óculos, relógios ou joias), } \\
\text { gerando dificuldade no } \\
\text { atendimento ao procurar } \\
\text { mercadorias dispersas. }\end{array}$ & $\begin{array}{l}\text { Alteração do local das vitrines, trazendo amplitude } \\
\text { para o espaço do cliente, assim como uma melhor } \\
\text { circulação. Cliente com acesso visual à todas as } \\
\text { vitrines do interior do estabelecimento; } \\
\text { A vitrines foram aproximadas e setorizadas de } \\
\text { acordo com o tipo de mercadoria; }\end{array}$ \\
\hline $\begin{array}{c}\text { 9. Adaptações para o } \\
\text { uso }\end{array}$ & $\begin{array}{c}\text { Placa de vidro na parede da } \\
\text { bancada de consertos para evitar } \\
\text { que pingue ácido no local; gaveta } \\
\text { adaptada para recolhimento do } \\
\text { pó de ouro; posicionamento de } \\
\text { maquinário na área da copa sem } \\
\text { nenhum isolamento por falta de } \\
\text { espaço. }\end{array}$ & $\begin{array}{l}\text { Proteção o na parede dos consertos em vidro para } \\
\text { não pingar ácido inapropriadamente; } \\
\text { Gaveta da bancada de trabalho com bandeja em } \\
\text { Inox para o recolhimento dos resíduos; Separação } \\
\text { da Copa e Área de polimento e Torno com o uso de } \\
\text { porta de correr. }\end{array}$ \\
\hline 10. Subprodutos de uso & $\begin{array}{c}\text { Presença de erosões, em } \\
\text { destaque para o desgaste dos } \\
\text { móveis. } \\
\text { Presença de sobras como } \\
\text { equipamentos, totens, catálogos } \\
\text { e produtos de propagandas, } \\
\text { assim como documentos e } \\
\text { objetos pessoais em locais } \\
\text { inadequados. }\end{array}$ & $\begin{array}{l}\text { Criação de um mobiliário mais bem aproveitado, } \\
\text { com espaço ampliado, locação de armários aéreos e } \\
\text { gaveteiros com rodízios; Leiaute com redução de } \\
\text { itens de propaganda. }\end{array}$ \\
\hline
\end{tabular}

Fonte: Pesquisadoras

A figura 02 relaciona os problemas encontrados na configuração atual e as recomendações propostas em nova configuração. O novo leiaute contempla uma separação maior entre o setor de conserto e o atendimento ao público. Isso justifica-se porque a importância do serviço de consertos para captação de clientes. Além disso, destacam-se na nova proposta: uma ampliação e nova setorização das bancadas de conserto; o isolamento do setor administrativo com divisórias de vidro; a reconfiguração do espaço de recepção/ atendimento ao cliente, com novas vitrines; a criação de espaço isolado para equipamentos na copa.

Se, na análise dos aspectos ergonômicos e comportamentais observados o foco da avaliação foi dado aos trabalhadores - para seu conforto, eficiência, segurança e bem-estar isso não exclui a importância do cliente como usuário. Cabe evidenciar que a valorização da experiência do cliente pode ser enriquecida pela coerência das instalações físicas com o posicionamento do negócio e com atenção aos aspectos humanizadores. 
Figura 02 - Antes e depois do ambiente (problemas > recomendações)

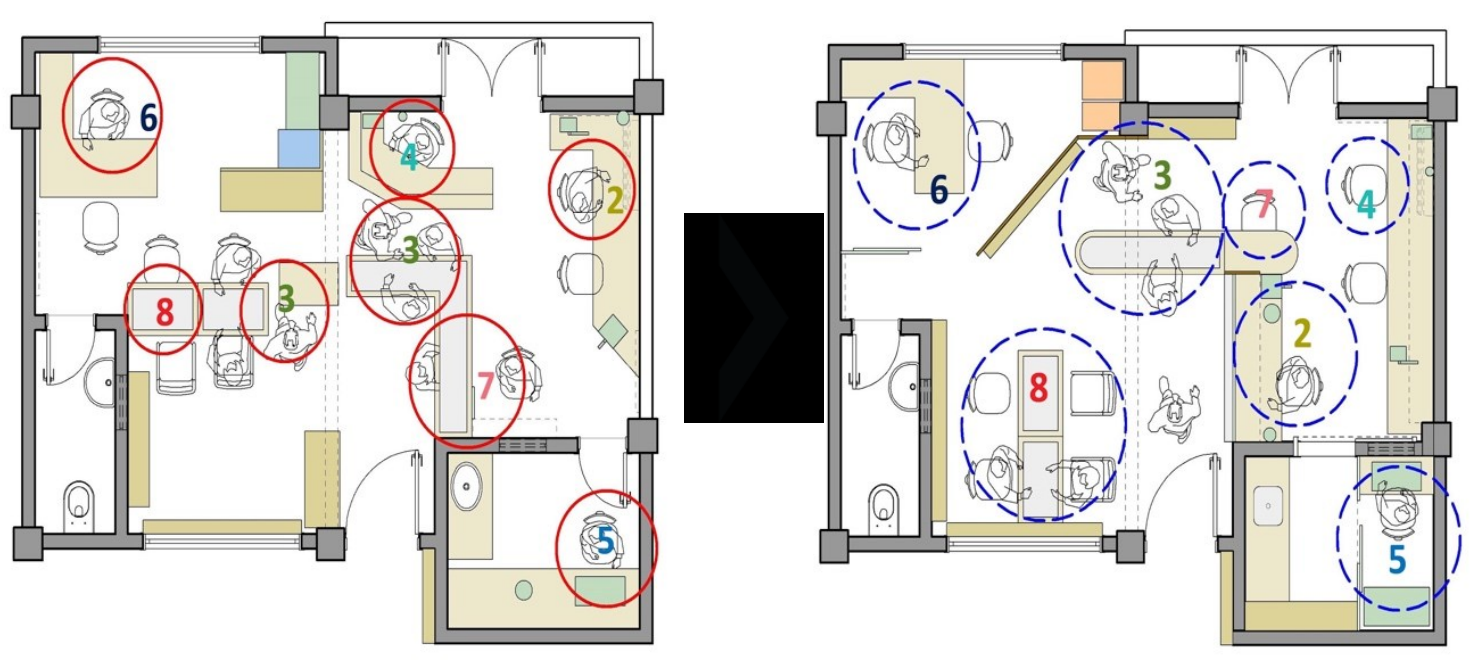

Fonte: Pesquisadoras

Os círculos à esquerda da Figura 02 destacam os principais problemas existentes e, à direita, uma nova planta baixa apresenta recomendações para melhorias de projeto. Estas se relacionam com a Tabela 02 apresentada através da numeração (de 1 a 10) das categorias escolhidas, permitindo a identificação do local no qual o problema foi apontado e também a situação na qual a recomendação sugerida foi aplicada ao novo projeto.

Além destes aspectos, ressaltam-se outros relacionados ao marketing. A empresa não possui ações institucionais ou promocionais além das instalações de PDV, embalagens e os itens básicos de identidade corporativa (logomarca, cartões de vistas, etc.). Isso reforça a relevância e necessidade de adequação do ambiente do PDV como construtor de marca e reputação do negócio, além da exposição e venda dos produtos.

\section{CONSIDERAÇÕES FINAIS}

A premissa inicial de que a qualidade de um ambiente se evidencia pelo atendimento às necessidades de seus usuários e suas atividades foi acrescida, neste estudo, do atendimento às necessidades do negócio. Por uma combinação de instalações antigas, problemas ergonômicos, comportamentos adaptativos e estratégias de marketing inadequadas ao momento atual do negócio, o conceito de reposicionamento deu um enfoque integrador à avaliação ambiental.

A abordagem transdisciplinar foi fundamental para abranger a complexidade de interações entre o ambiente, os usuários, suas atividades e o negócio. A pesquisa bibliográfica possibilitou elencar os conceitos mais relevantes, a definição da metodologia e os critérios de pesquisa. $O$ uso de múltiplos instrumentos mostrou-se eficiente para a investigação da qualidade ambiental do PDV estudado, permitindo uma rica coleta de dados e uma melhor compreensão de todas as interações.

É notável como a boa relação entre os trabalhadores do local alimenta a satisfação com o ambiente de trabalho, otimizando sua percepção de qualidade ambiental. O cruzamento de todos os dados coletados permitiu uma identificação ampla dos aspectos problemáticos e positivos, superando a percepção inicial das pesquisadoras e auxiliando na definição de um enfoque integrador para a avaliação. A análise, portanto, fundamentou o diagnóstico e as recomendações propostas.

Além dos aspectos ambientais, cabe ressaltar outro aspecto de natureza distinta. Embora a diversificação do trabalho permita alternância entre as atividades de consertos e atendimento ao cliente, com picos de esforço e pausa, essa dinâmica gera algumas sobrecargas que podem vir a prejudicar a saúde dos trabalhadores com o tempo. 
Especialmente na função administrativa, que é acumulativa com atendimento e consertos, a sobrecarga é também mental. Talvez a presença de um atendente dedicado exclusivamente aos clientes possa contribuir na melhoria organizacional.

\section{REFERÊNCIAS}

BRASIL, MINISTÉRIO DO TRABALHO E EMPREGO. Classificação Brasileira de Ocupações. Disponível em: <http://www.mtecbo.gov.br/cbosite/pages/pesquisas/BuscaPorTituloResultado.jsf> (acesso em junho de 2016)

BINS Ely, V. Ergonomia + Arquitetura: buscando um melhor desempenho do ambiente físico. In: Anais do $3^{\circ}$. Ergodesign $-3^{\circ}$. Congresso Internacional de Ergonomia e Usabilidade de interfaces humano-tecnologia: Produtos, programa, informação, ambiente construído. Rio de Janeiro. LEUI/PUC - Rio, 2003.

BINS ELY, Vera Helena Moro; TURKIENICZ, Benamy. Método da grade de atributos: avaliando a relação entre usuário e ambiente. In: Ambiente Construído, v. 5, n. 2, p. 77-88, abr./jun. Porto Alegre, 2005.

CYBIS, Walter; BETIOL, Adriana Holtz; FAUST, Richard. Ergonomia e usabilidade: conhecimentos, métodos e aplicações. São Paulo: Novatec, 2007. 344p.

FALZON, Pierre. Natureza, objetivos e conhecimentos da ergonomia: elementos de uma análise cognitiva da prática. In: Falzon, P. (editor). Ergonomia. São Paulo: Blucher, 2007.

GUÉRIN, F., LAVILLE, A., DANIELLOU, F., DURAFOURG, J., KERGUELEN, A. Compreender o trabalho para transformá-lo: a prática da ergonomia. São Paulo, Blucher, Fundação Vanzolini. 2001.

KOETLER, Philip. Marketing para o século XXI: como criar, conquistar e dominar mercados. São Paulo: Editora Futura, 2000.

KOHLSDORF, Maria Elaine. Percepção do espaço e ensino de projetação. I Encontro de Percepção e Paisagem da Cidade. São Paulo, 2006.

KUORINKA, I.; JONSSON, B.; BIERING-SORENSEN, F.; ANDERSSON, G.; VINTENBERG, H.; JORGENSEN, K. Standardized Nordic Questionnaires for the Analysis of Musculoskeletal Symptoms. Applied Ergonomics, v. 18, n. 3, p. 233-37, 1987.

LOMBARDO, Thomas J. The Reciprocity of Perceiver and Environment: the Evolution of James J. Gibson`s ecological Psychology. Londres: Lawrence Erlbaum Associates, 1987.

MORAES, Anamaria de; MONT'ALVÃO, Cláudia. Ergonomia: conceito e aplicações. Rio de Janeiro: iUsEr, 2003.

MORAES, Anamaria de; MONT'ALVÃO, Cláudia. Ergonomia no Ambiente Construído: Teoria e Prática. In: MORAES, Anamaria de (org.). Ergodesign do Ambiente Construído e Habitado: Ambiente Urbano, Ambiente Público, Ambiente Laboral. Rio de Janeiro: iUsEr, 2004.

NORBERG-SCHULZ, Christian. O fenômeno do lugar. [artigo] in NESBITT, Kate (org.). Uma nova agenda para a arquitetura. Antologia Teórica 1965-1995. 2ª ed. São Paulo: Cosac Naify, 2013.

OLIVEIRA, Gilberto Rangel de; MONT'ALVÃO, Cláudia. Metodologias utilizadas nos estudos de ergonomia do ambiente construído e uma proposta de modelagem para projetos de design de interiores. $15^{\circ}$ Ergodesign, Recife, 2015.

TISSOT, Juliana Tasca. Definição de atributos arquitetônicos essenciais para a humanização em quartos de internação [dissertação de mestrado]. Florianópolis: Universidade Federal de Santa Catarina, 2016.

UNDERHILL, Paco. Vamos às Compras!: a ciência do consumo nos mercados globais. Rio de Janeiro: Elsevier,2009.

VILLAROUCO, Vilma. An ergonomic look at the work environment. In: Proceeding from IEA 09: 17th World Congress on Ergonomics. China: Beijing, 2009.

ZEISEL, John. Inquiry by design: environment/ behavior/ neuroscience in Architectures, Interiors, Landscape, and Planning. New York: W.W. Norton \& Company. Revised Edition, 2006. 